\title{
The Bibliometric Aspects of Case Report/Series in Science Citation Index Otorhinolaryngology Journals
}

\author{
Original Investigation $>$ (1) Nesibe Gül Yüksel Aslıer¹, (1) Mustafa Aslıer² \\ ${ }^{1}$ Department of Otorhinolaryngology, University of Health Sciences Turkey, Bursa Yüksek İhtisas Training and \\ Research Hospital, Bursa, Turkey \\ ${ }^{2}$ Department of Otorhinolaryngology, Uludağ University School of Medicine, Bursa, Turkey
}

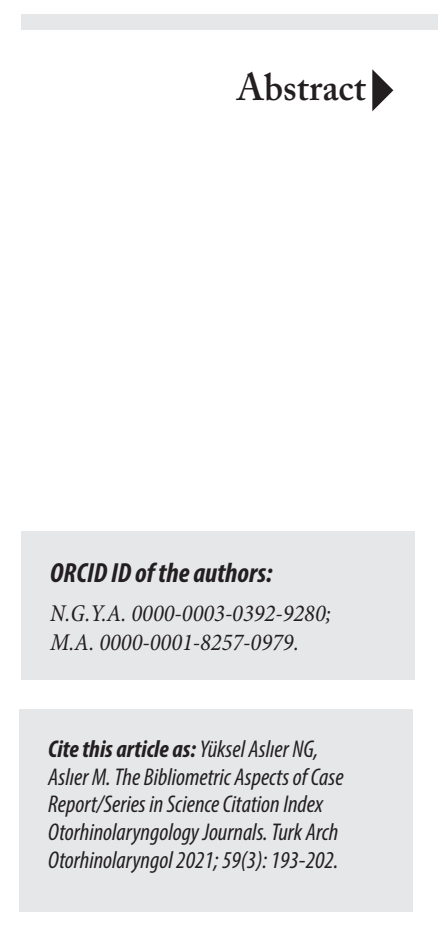

Corresponding Author:

Nesibe Gül Yüksel Aslıer; nesibe.gul.yuksel@gmail.com

Received Date: 18.04 .2021

Accepted Date: 29.08 .2021

Content of this journal is licensed under a Creative Commons Attribution 4.0 International License. Available online at www.turkarchotolaryngol.net

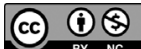

D0l: 10.4274/tao.2021.2021-4-12

Objective: The rate of case report/series (CR/S) acceptance by the high impact journals is steadily declining mainly due to low citations. The aim of this study is primarily to investigate the bibliometric aspects of $\mathrm{CR} / \mathrm{S}$ in the field of otorhinolaryngology (ORL) and secondarily to guide prospective authors as to which type of $\mathrm{CR} / \mathrm{S}$ have better chances of acceptance and citation in the current publication climate.

Methods: Bibliometric and citation analysis of CR/S published in Science Citation Index (SCI) journals of ORL covering the years of 2012-2016 was conducted.

Results: There were 1332 (8.9\%) CR/S among 14900 publications in 11 SCI ORL journals published between January $1^{\text {st }}, 2012$ and December $31^{\text {st }}, 2016$. The most common published field and subject were the 'pediatric ORL' (33.2\%) and 'rare cases/conditions' (47.1\%) respectively. 'General ORL' (5.13) and 'treatment' (4.93) categories had the highest citations. Only $10 \%$ of $\mathrm{CR} / \mathrm{S}$ had $\geq 10$ citations. The mean citation counts were positively correlated with impact factors of journals $(\mathrm{r}=0.131, \mathrm{p}<0.001)$, mean number of authors $(\mathrm{r}=0.151, \mathrm{p}<0.001)$, mean number of cases $(\mathrm{r}=0.192, \mathrm{p}<0.001)$, mean number of references $(\mathrm{r}=0.315, \mathrm{p}<0.001)$ and mean number of Web of Science visits $(\mathrm{r}=0.291, \mathrm{p}<0.001)$.

Conclusion: Although CR/S provides low citation rates in ORL SCI journals, they may serve important topics in terms of diagnosis, treatment, or complications. The findings and the main discussions of this study may direct the rationale for the consistent publication of $\mathrm{CR} / \mathrm{S}$ in the evidence-based medicine era.

Keywords: Bibliometrics, case report, case series, citation analysis, otorhinolaryngology, abstracting and indexing

\section{Introduction}

In the last few decades, the place of case report or series $(\mathrm{CR} / \mathrm{S})$ in the era of evidence-based medicine (EBM) has been changing. However, in the past, physicians recognized and consequently treated rare conditions with the help of reports presented by their colleagues (1). 
Furthermore, the emergence of CR/S dates back to ancient Egypt and it still has didactic value today likewise those times (2).

Because CR is often considered as being unscientific or of little scientific value, there is still not a consensus on the worth of publishing CR/S in the EBM age (3). The Science Citation Index (SCI), an online database of Web of Science (WoS) platform, calculates the impact factor (IF) of a journal annually according to the number of citations made to the publications of that journal (4). While meta-analysis and prospective randomized controlled studies come to the fore with this concept, CR/S, which are at the bottom of the hierarchy of evidence, have lost their importance to a great extent $(1,3)$. Since IF is determined by the number of citations the publications receive, editors tend to publish as few $\mathrm{CR} / \mathrm{S}$ as possible in their journals (5-7).

In this study, we aimed to make quantitative and qualitative analysis of the articles in the category of $\mathrm{CR} / \mathrm{S}$ published in $16 \mathrm{SCI}$ journals of Otorhinolaryngology (ORL) field with respect to their bibliometric characteristics and citation data. As a secondary aim, we tried guiding authors about the current trend in the acceptance of CR/S in high impact ORL SCI journals.

\section{Methods}

The citation analysis with bibliometric characteristics of $\mathrm{CR} / \mathrm{S}$, which were published in ORL journals indexed in SCI category during the period January ${ }^{\text {st }}, 2012$ and December $31^{\text {st }}, 2016$ was conducted. Any study, conducted for citation analysis, is better designed to include the data of the secondthird year prior to the date of the study as the most recently, to be able to collect citations. That was the reasonableness of the time period choice in this study. In order to design a nonbiased journal sample, we preferred to select ORL journals listed in 'SCI', which was the actual journal listing for highimpact journals at the time of the study.

Total number of articles in each journal and the number of $\mathrm{CR} / \mathrm{S}$ were manually collected by screening journal issues. We defined CR/S by looking at how the journal classified the paper on its official website. If that knowledge was not available, the article was defined as CR/S or not, according to the methodology of the paper. The following types of texts were excluded; e-report article only, proceedings article, early printing, conference notes, meeting/congress abstracts, comments, reflections, highlights, corrections, historical reports, specific focus sections, erratum, corrigendum, discussions, biographic items, retracted papers, clinical practical guideline supplements, meeting/conference programs, editorials, list of reviewers and invited editor talks. The clinical problem solving and video cases were excluded as well.
After listing the articles, the two authors reviewed data separately. They included the reports published under the journals' category of 'case report' or 'case report/case series', plus, when the journal was lack of this classification; they included the study if study design was stated as CR/S in the article.

\section{Research Sample}

There were 16 SCI indexed ORL journals between 20212016. Among the journals, 'Dysphagia', as it is more specific to pharyngo-esophageal disorders, and 'Journal of the Association for Research in Otolaryngology (JARO)', as it publishes particular type of scientific reports, were excluded. The journal of 'Otolaryngologic Clinics of North America' was also excluded because it only publishes reviewtype articles. There were 1,336 (8.4\%) articles under CR/S category (among 16,207 articles) in 13 SCI ORL journals covering the period 2012-2016. Additionally, the journals of 'Hearing Research' (with only one multifamily study) and 'Ear and Hearing' (with only three case studies) were excluded as well. After exclusions, there remained 1,332 (8.9\%) CR/S articles from 51 countries (among 14,900 papers in 11 journals).

Before conducting analysis regarding citations, 9 papers (three CR/S with 11 cases, one with 12 cases, two with 15 cases, one with 16 cases, one with 18 cases and one with 67 cases), which have case numbers above 10 , were extracted to let the rest of the articles more likely be defined as case reports.

\section{Categorization of Bibliometric Features}

The subspecialties of ORL were categorized as otology, rhinology, general ORL (benign ORL disorders other than malignant diseases: infections, benign head and neck tumors, thyroid disease and obstructive sleep apnea), head and neck oncology, laryngology, pediatric ORL (reports of cases under the age of 18 years) and facial plastic surgery. There were only two CR/S in the field of facial plastic surgery; therefore, they were placed to the section of rhinology. According to their subjects, $\mathrm{CR} / \mathrm{S}$ were observed in the categories of rare condition/disease/anatomy, etiology/symptomatology, foreign body/trauma, diagnostic tool/examination, medical or surgical treatment, complications and unexpected conditions, pathology, genetics and audiology. To provide a more accurate analysis, the types of study subjects were classified under four main categories particularly for this study; rare cases (rare condition/disease/anatomy, foreign body, trauma, etiology/symptomatology), diagnosis and examination (diagnostic tool/examination diagnosis, pathology, genetics and audiology), treatment, and finally complications. 


\section{Citation Analysis}

The WoS database was evaluated in terms of citations between October $20^{\text {th }}$ and $26^{\text {th }}, 2019$. Typing the whole title of the manuscript at the section of 'title' on the search page, the data provided by the database were collected. The count of citations and WoS visits were obtained from the citation report of WoS. The values of IFs for 2018/2019 periods were noted from both the journal websites and the http://www. bioxbio.com/if/ on $10^{\text {th }}$ of December 2019 (8).

\section{Statistical Analysis}

The relationship of correlation between variables was evaluated by Spearman's correlation test. Continuous variables were also compared among different groups using Mann-Whitney U or Kruskal-Wallis tests. Cross-tabs with likelihood ratios were used to analyze categorical variables among the different groups. All statistical analyses were performed using the SPSS 20.0 software package $\left(\mathrm{IBM}^{\oplus}\right.$ SPSS $^{\oplus}$ Statistics 20.0, Armonk, N.Y., USA). The results were evaluated with $95 \%$ confidence intervals, and $p<0.05$ was considered as statistically significance level.

Ethics committee approval was not obtained for this study, as no human subject was included in this bibliometric research.

\section{Results}

A total of 14,900 articles were published in 11 SCI ORL journals within a five-year period covering 2012-2016, of which 1,332 were $(8.94 \%) \mathrm{CR} / \mathrm{S}$. The bibliometric characteristics of journals regarding CR/S are given in Table 1. The trend for publications of $\mathrm{CR} / \mathrm{S}$ according to the years is shown in Figure 1.

The journals with CR/S publication rates of more than $10 \%$ were as follows; 'Head \& Neck' (16.5\%), 'International Journal of Pediatric Otorhinolaryngology' (14.8\%), 'Annals of Otology, Rhinology \& Laryngology' (13.6\%) and 'Otology \& Neurotology' (11\%).

The most common subspecialty of ORL was the pediatric ORL ( $\mathrm{n}=442,33.18 \%)$, followed by otology $(\mathrm{n}=284,21.32 \%)$,

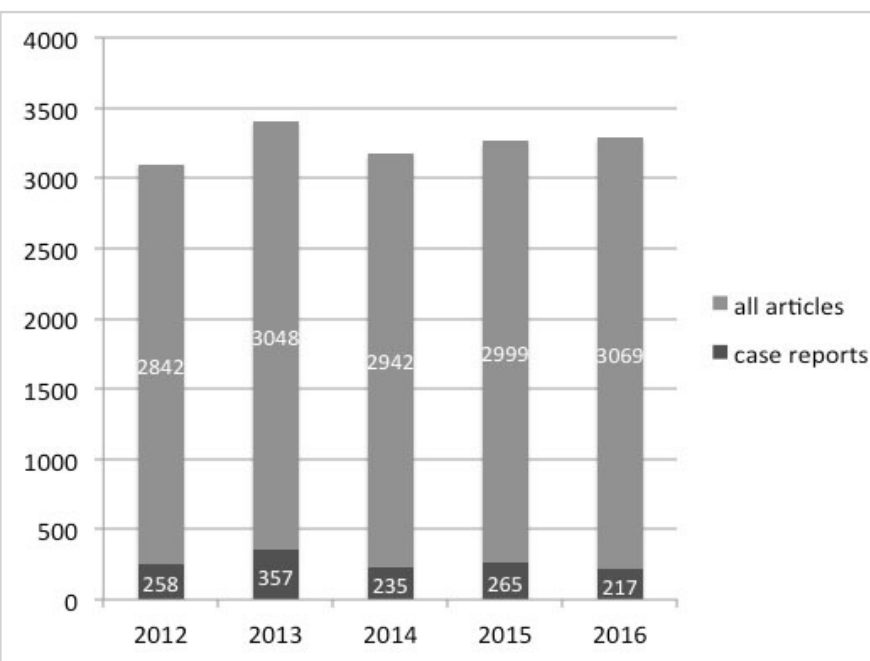

Figure 1 . The number of case report/series among all articles and trends in years covering 2012-2016

Table 1. Frequency findings of the case report/series with respect to the numbers, percentage among all articles, year of publication, institution and department of the first author of the study

\begin{tabular}{|c|c|c|c|c|c|c|c|c|c|c|c|c|}
\hline \multirow[b]{2}{*}{ Journal name* } & \multirow{2}{*}{$\begin{array}{l}\text { Total article } \\
\text { number (n) }\end{array}$} & \multirow{2}{*}{$\begin{array}{l}\text { Case report } \\
\mathrm{n}(\%)\end{array}$} & \multicolumn{5}{|l|}{ Year } & \multicolumn{3}{|l|}{ Institution } & \multicolumn{2}{|c|}{ Department } \\
\hline & & & 2012 & 2013 & 2014 & 2015 & 2016 & University & General & Private & ORL & Other \\
\hline Acta Otolaryngol. & 1,022 & $8(0.78 \%)$ & 7 & 0 & 0 & 1 & 0 & 5 & 3 & 0 & 6 & 2 \\
\hline Am J Rhinol Allergy. & 657 & $3(0.46 \%)$ & 0 & 0 & 0 & 2 & 1 & 3 & 0 & 0 & 3 & 0 \\
\hline $\begin{array}{l}\text { Ann Otol Rhinol } \\
\text { Laryngol. }\end{array}$ & 765 & $104(13.59 \%)$ & 14 & 18 & 24 & 29 & 19 & 84 & 19 & 1 & 100 & 4 \\
\hline Audiol Neurootol. & 209 & $12(5.74 \%)$ & 3 & 2 & 5 & 1 & 1 & 11 & 0 & 1 & 12 & 0 \\
\hline Clin Otolaryngol. & 620 & $22(3.55 \%)$ & 6 & 7 & 3 & 3 & 3 & 21 & 0 & 1 & 22 & 0 \\
\hline Head Neck. & 1,589 & $262(16.49 \%)$ & 19 & 96 & 36 & 51 & 60 & 241 & 13 & 8 & 147 & 115 \\
\hline $\begin{array}{l}\text { Int J Pediatr } \\
\text { Otorhinolaryngol. }\end{array}$ & 2,275 & $337(14.81 \%)$ & 51 & 70 & 81 & 86 & 49 & 295 & 30 & 12 & 283 & 54 \\
\hline $\begin{array}{l}\text { JAMA Otolaryngol } \\
\text { Head Neck Surg. }\end{array}$ & 1,205 & $66(5.48 \%)$ & 24 & 9 & 16 & 10 & 7 & 55 & 2 & 9 & 57 & 9 \\
\hline Laryngoscope. & 3,028 & 201 (6.64\%) & 38 & 73 & 29 & 33 & 28 & 191 & 6 & 4 & 192 & 9 \\
\hline $\begin{array}{l}\text { Otolaryngol Head } \\
\text { Neck Surg. }\end{array}$ & 1,782 & $126(7.07 \%)$ & 43 & 33 & 19 & 23 & 8 & 122 & 4 & 126 & 125 & 1 \\
\hline Otol Neurotol. & 1,748 & $191(10.98 \%)$ & 53 & 49 & 22 & 26 & 41 & 181 & 10 & 0 & 182 & 9 \\
\hline Total & 14,900 & $1332(8.94 \%)$ & 258 & 357 & 235 & 265 & 217 & 1209 & 87 & 162 & 1129 & 203 \\
\hline
\end{tabular}


head and neck oncology ( $\mathrm{n}=250,18.77 \%)$, general ORL $(\mathrm{n}=208,16.62 \%)$, rhinology $(\mathrm{n}=83,6.23 \%)$ and laryngology $(\mathrm{n}=65,4.88 \%)$ respectively (Table 2$)$. The category of rare cases $(47.1 \%)$ and treatment $(26.8 \%)$ were the most common main subjects (Table 3 ).

The only significant contingencies were between the subspecialty of the ORL and subject of the CR/S ( $<<0.001)$. Laryngology was out of the usual trend and the CR/S about the treatments and complications in this field were more common than the other subspecialties of ORL. Most (>50\%) of $\mathrm{CR} / \mathrm{S}$ were about rare cases in the fields of Otology, Rhinology, General ORL and Pediatric ORL.
Of 1332 CR/S, 258 (19.37\%) failed to have citations. The percentage of $\mathrm{CR} / \mathrm{S}$, which had only one citation at the time of this study, was $21.02 \%(n=280)$. One hundred twenty-four (9.31\%) CR/S had $\geq 10$ citations. The highest mean citation counts were belonging to 'Head and Neck' and 'American Journal of Rhinology and Allergy', which were 5.69 and 5.67, respectively (Table 4). 'American Journal of Rhinology and Allergy' seems to be the most citation-effective journal with lowest number of CR/S but highest number of citations.

International journals tended to publish $\mathrm{CR} / \mathrm{S}$ not only from the American or European countries, but also from worldwide. USA (48\%) stood first with the highest number of CR/S publications in this study, followed by Japan (6.1\%), Italy (4.7\%) and Canada (4.1\%).

Table 2. Frequency findings of the case report/series with respect to the fields of Otorhinolaryngology

\section{Subspecialties of ORL, $\mathrm{n}(\%)$}

\begin{tabular}{|c|c|c|c|c|c|c|}
\hline Journal name* & Otology & Rhinology & GORL & HNO & Laryngology & Ped. ORL \\
\hline Acta Otolaryngol. & $7(87.5 \%)$ & $0(0.0 \%)$ & $0(0.0 \%)$ & $0(0.0 \%)$ & $0(0.0 \%)$ & $1(12.5 \%)$ \\
\hline Am J Rhinol Allergy. & $0(0.0 \%)$ & $2(66.7 \%)$ & $0(0.0 \%)$ & $1(33.3 \%)$ & $0(0.0 \%)$ & $0(0.0 \%)$ \\
\hline Ann Otol Rhinol Laryngol. & $33(31.7 \%)$ & $5(4.8 \%)$ & $22(21.2 \%)$ & $10(9.6 \%)$ & $13(12.5 \%)$ & $21(20.2 \%)$ \\
\hline Audiol Neurootol. & $9(75 \%)$ & $0(0.0 \%)$ & $0(0.0 \%)$ & $0(0.0 \%)$ & $0(0.0 \%)$ & $3(25 \%)$ \\
\hline Clin Otolaryngol. & $5(22.7 \%)$ & $6(27.3 \%)$ & $1(4.5 \%)$ & $5(22.7 \%)$ & $3(13.6 \%)$ & $2(9.1 \%)$ \\
\hline Head Neck. & $5(1.9 \%)$ & $5(1.9 \%)$ & $71(27.1 \%)$ & $174(66.4 \%)$ & $0(0.0 \%)$ & $7(2.7 \%)$ \\
\hline Int J Pediatr Otorhinolaryngol. & $0(0.0 \%)$ & $0(0.0 \%)$ & $0(0.0 \%)$ & $0(0.0 \%)$ & $0(0.0 \%)$ & $337(100 \%)$ \\
\hline JAMA Otolaryngol Head Neck Surg. & $13(19.7 \%)$ & $11(16.7 \%)$ & $14(21.2 \%)$ & $3(4.5 \%)$ & $10(15.2 \%)$ & $15(22.7 \%)$ \\
\hline Laryngoscope. & $29(14.4 \%)$ & $31(15.4 \%)$ & $52(25.9 \%)$ & $28(13.9 \%)$ & $29(14.4 \%)$ & $32(15.9 \%)$ \\
\hline Otolaryngol Head Neck Surg. & $20(15.9 \%)$ & $23(18.3 \%)$ & $42(33.3 \%)$ & $15(11.9 \%)$ & $10(7.9 \%)$ & $16(12.7 \%)$ \\
\hline Otol Neurotol. & $163(85.3 \%)$ & $0(0.0 \%)$ & $6(3.1 \%)$ & $14(7.3 \%)$ & $0(0.0 \%)$ & $8(4.2 \%)$ \\
\hline Total & $284(21.3 \%)$ & $83(6.2 \%)$ & $208(16.6 \%)$ & $250(18.8 \%)$ & $65(4.9 \%)$ & $442(33.2 \%)$ \\
\hline
\end{tabular}

GORL: General Otorhinolaryngology, HNO: Head and Neck Oncology, ORL: Otorhinolaryngology, Ped. ORL: Pediatric Otorhinolaryngology, n: Number

*Abbreviated name of the journals

Table 3. Frequency findings of the case report/series with respect to the subject groups

\begin{tabular}{lllll}
\hline & \multicolumn{2}{l}{ Subgroups of Subject, $\mathbf{n}(\%)$} & & \\
\hline Journal name* & Rare case & Examination & Treatment & Complication \\
\hline Acta Otolaryngol. & $3(37.5 \%)$ & $1(12.5 \%)$ & $4(50 \%)$ & $0(0.0 \%)$ \\
\hline Am J Rhinol Allergy. & $2(66.6 \%)$ & $0(0.0 \%)$ & $1(33.3 \%)$ & $0(0.0 \%)$ \\
\hline Ann Otol Rhinol Laryngol. & $55(52.9 \%)$ & $11(10.6 \%)$ & $29(27.9 \%)$ & $9(8.7 \%)$ \\
\hline Audiol Neurootol. & $0(0.0 \%)$ & $8(66.7 \%)$ & $4(33.3 \%)$ & $0(0.0 \%)$ \\
\hline Clin Otolaryngol. & $0(0.0 \%)$ & $0(0.0 \%)$ & $21(95.5 \%)$ & $1(4.5 \%)$ \\
\hline Head Neck. & $112(42.7 \%)$ & $34(13 \%)$ & $99(37.8 \%)$ & $17(6.5 \%)$ \\
\hline Int J Pediatr Otorhinolaryngol. & $191(56.7 \%)$ & $28(8.3 \%)$ & $77(22.8 \%)$ & $41(12.2 \%)$ \\
\hline JAMA Otolaryngol Head Neck Surg. & $38(57.6 \%)$ & $10(15.2 \%)$ & $7(10.6 \%)$ & $11(16.7 \%)$ \\
\hline Laryngoscope. & $97(48.3 \%)$ & $8(4.0 \%)$ & $82(40.8 \%)$ & $14(7.0 \%)$ \\
\hline Otolaryngol Head Neck Surg. & $82(65.1 \%)$ & $1(0.8 \%)$ & $28(22.2 \%)$ & $15(11.9 \%)$ \\
\hline Otol Neurotol. & $163(85.3 \%)$ & $14(7.3 \%)$ & $5(2.6 \%)$ & $9(4.7 \%)$ \\
\hline Total & $743(55.8 \%)$ & $115(8.6 \%)$ & $357(26.8 \%)$ & $117(8.8 \%)$ \\
\hline n: Number & & & & \\
\hline$*$ Abbreviated name of the journals & & & & \\
\hline
\end{tabular}




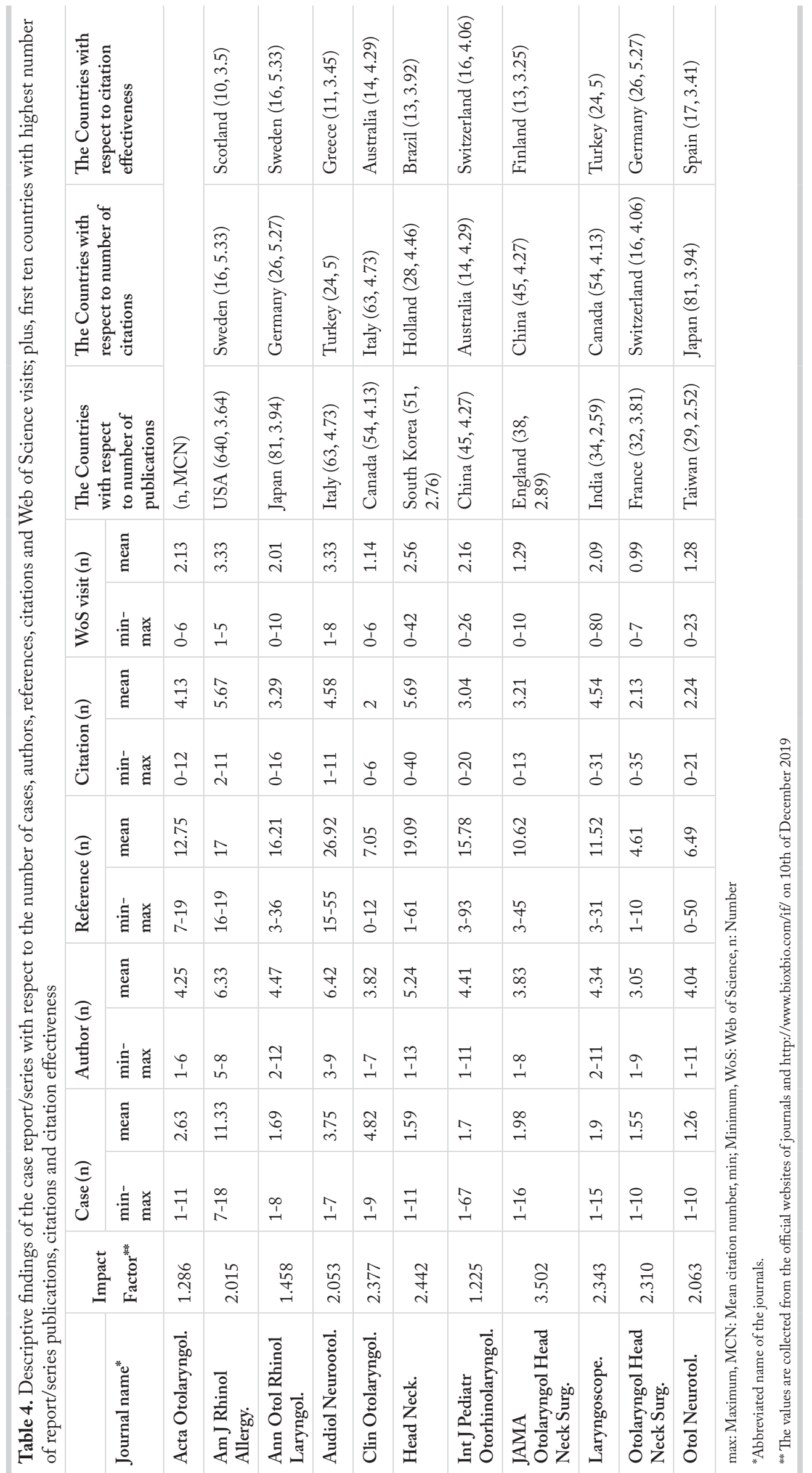


Table 4 shows the first ten countries with the highest number of $\mathrm{CR} / \mathrm{S}$ publications, citations and citation effectiveness.

The mean citation numbers were statistically different between all subgroups of study subjects and ORL subspecialties $(p<0.05)$. New treatments/surgical techniques (4.93) and new examinations/diagnostic tools (4.46) gathered the highest number of citations. The mean number of citations for rare cases and complication topics were 2.96 and 2.86, respectively. The subspecialty of General ORL diseases received the highest number of citations (5.13), followed by rhinology (4.07), head and neck oncology (3.85), pediatric ORL (3.13), laryngology (2.97) and otology (2.85). The first authors of other specialties showed a higher number of citations ( 5.27 vs. 3.31$)$ than otolaryngologists $(p<0.05)$.

There were positive correlations between the value of IFs of the journals with mean citation counts of $\mathrm{CR} / \mathrm{S}(\mathrm{r}=0.131$, $\mathrm{p}<0.001)$ and mean author numbers $(\mathrm{r}=0.061, \mathrm{p}=0.027)$. The mean citation counts were positively correlated with the mean number of authors $(r=0.151, p<0.001)$, mean number of cases $(r=0.192, p<0.001)$, mean number of references $(\mathrm{r}=0.315, \mathrm{p}<0.001)$ and mean number of WoS visits $(\mathrm{r}=0.291$, $\mathrm{p}<0.001)$ as well.

Finally, descriptive characteristics of the most cited ten CR/S published in the studied five years in SCI ORL journals are summarized in Table 5.

\section{Discussion}

There are many bibliometric studies, especially about the citations the articles receive, but this report is detailed for solely case reports in our field. Therefore, the findings of this study bring important perspective to the bibliometrics of the case reports in ORL. The striking point of the present study is the low citation rates that only $10 \%$ of CR/S articles in ORL journals of SCI category (published during the period January $1^{\text {st }}, 2012$ and December $31^{\text {st }}, 2016$ ) had $\geq 10$ citations by October 2019 .

The case presentations can be stimulating for the reader. When a physician confronts with a collection of history, symptoms and signs; it is human nature for him to consider the most common disorders at first. However, thanks to the similar CR/S reported in literature, one can notice the rarer conditions or figure out the new treatment modalities. Before the modern science age, reporting $\mathrm{CR} / \mathrm{S}$ was the basic way to document rare conditions and to provide an environment for discussing difficult cases. But, in recent times, the existence of massive information and easy online access to resources has replaced their needs (1).

Nevertheless, there are still conflicts about the definition of case reports and case series or case studies in the literature (5-7). A case report is defined as a detailed description of the experience gathered from a single patient $(1,9)$. If more than one case is reported, it is called a case series or case series report. They usually consist of 3-10 cases (10). In 2008, Glossary of Epidemiology (11) defined 'case series' as follows; "A collection of patients with common characteristics used to describe some clinical, pathophysiological, or operational aspect of a disease, treatment, or diagnostic procedure." However, the term of 'case reports' was described as; "Detailed descriptions of a few patients or clinical cases (frequently, just one sick person) with an unusual disease or complication, uncommon combinations of diseases, and unusual or misleading SEMIOLOGY, CAUSE or OUTCOME (may be surprising recovery...)"(11). However, in 2001, the Glossary of Epidemiology (12) explained nothing for CR/S, indicating that an epidemiologist had tried defining these terms at the early 2000s (13).

To moderate the above discussions, we suggest the following definitions; case presentation or report is a descriptive article on a single case; whereas, case series is a descriptive article on multiple cases with common rare condition/ disease/anatomy/pathology/genetic structure. Apart from them, a case study can be retrospective, cross-sectional or prospectively followed and/or may include further analysis regarding new cases/methodologies/experimental findings or novel treatment techniques. Therefore, if the article is original and analytic; it is not recommended to be identified as CR/S, accordingly any CR/S should not be accepted as an original article if it does not involve the research hypothesis (14). Consequently, the articles with research purposes or retrospective/prospective investigations on a respectable case sample would rather be accepted as case studies than $\mathrm{CR} / \mathrm{S}$ $(15,16)$. In the same way, CR/S are preferably unaccepted as analytical studies, but if only the descriptive aspects are specified; then they are identified as CR/S (17). To adhere to the formal categorization of the journals, the articles listed as $\mathrm{CR} / \mathrm{S}$ or stated as CR/S in their methods section were included in this study.

Even though CR/S have fallen out of favor in the era of $\mathrm{EBM}$, their place in academic medical publication should be promoted as they have potential educational benefits (18). In fact, there was a fluctuating but finally declining trend in publication rates of CR/S in the period of 2012-2016 in this study. We found an incidence of $8.94 \%$ for $\mathrm{CR} / \mathrm{S}$ among articles published in SCI ORL journals in the study period. This ratio corresponds to the recent $\mathrm{CR} / \mathrm{S}$ publishing tendencies in the field of medicine $(5,6,18,19)$. However, the frequency of $\mathrm{CR} / \mathrm{S}$ is $15.1 \%$ among ORL articles for the period between 1945-2016 (19), which supports the decline in our sample (Figure 1). Some journals, as a rule, do not intend to accept the submission of $\mathrm{CR} / \mathrm{S}$ at the initial stage or some recommend early rejection or desk rejection. Considering the fast-growing volume of scientific literature and their concern regarding earning citations, it seems that $\mathrm{CR} / \mathrm{S}$ have lost their value of evidence and become weaker in recent decades $(3,19)$. 


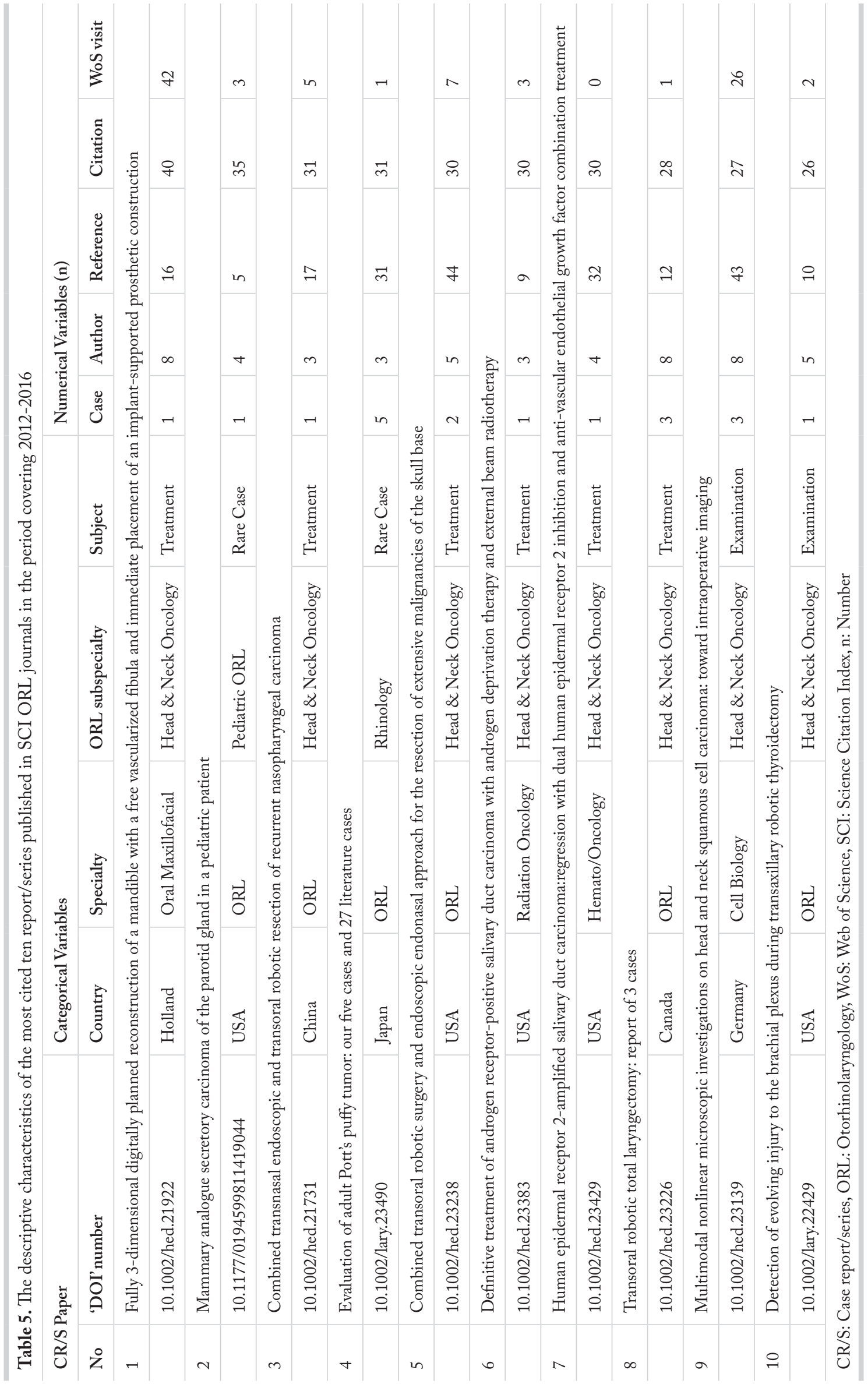


In this study, the field of General ORL diseases is in the first place for the highest mean citation number, followed by rhinology and head and neck oncology for CR/S. In the study by Coelho et al.(20) the fields, most frequently associated with citation classics, were otology and lateral skull base both in 1999 (48.75\%) and 2009 (55.71\%). Head and neck oncology, benign head and neck disorders and laryngology remained at similar citation rates in 1999 and 2009. Whereas, the number of rhinology and anterior skull base related citation classics declined in 2009 (10.50\%), compared to 1999 (17.50\%) for original articles (20). In the report of Lenzi et al.(21), the leading research field was otology/neurotology, followed by rhinology and head and neck surgery, for all article types. It seems that the ORL subspecialty with the most citation potential can vary according to the type of paper.

It has been shown that most of the CR/S in the ORL journals were under the rare cases class (7). On the other hand, only two of the most cited $10 \mathrm{CR} / \mathrm{S}$ were included in the category of rare cases. Indeed, 'new treatment' subject was the most frequent among these ten most cited CR/S (Table 5). In line with this finding, the highest citation rates were observed in the field of treatment (4.93+/-5.809) as well. It is an expected result that the case series, which have not yet had a large number of patients enough for reporting a clinical study, but where the results of an innovative surgical technique applied to a reasonable number of cases are reported, will receive more citations.

The most citation-effective publications were from Scotland, Sweden, Greece, Australia, Brazil, Switzerland, Finland, Turkey, Germany and Spain (Holland was the eleventh) in this study. In another study, the country of origin (for all type of publications) influenced the citation possibility and effectiveness as well (21). The journal 'Head \& Neck' (16.5\%) showed the highest percentage of publishing $\mathrm{CR} / \mathrm{S}$ and the highest mean citation count of 5.69 in this study.

In the report of Fenton et al. (22) in 2004, the number of citations to CR/S, published from January to December 2000, ranged from 3 to 28 (mean: 12.4) in Auris Nasus Larynx and 2 to 28 (mean: 10.2) in The Journal of Laryngology and Otology. Edelmeyer et al. (19) reported only three CR/S with more than 100 citations and were considered as 'citation classics'. Whereas, 905 citation classics were found in 2014, compared with 80 in 2001, for original articles (19). In this study, the highest citation count was 40 (Table 5).

The study by Laccourreye et al.(23) analyzed the reasons for acceptance and rejection for CR/S in 'European Annals of Otorhinolaryngology Head and Neck Diseases' and reported the most common flaws; in $74.5 \%$ of cases, as the lack of originality and lack of new data contributing to the medical literature. The number of $\mathrm{CR} / \mathrm{S}$ that SCI ORL journals have taken over the course of five years (2012-2016) has also declined a bit in this study. Similarly, as reported by
Edelmayer et al.(19) six of the top 10 ORL journals (by IF) did not publish CR/S anymore.

The evaluation of the CR/S in terms of the citations they receive shows that the index of journal plays an important role in the citation gain of the study. The interest of readers to the articles published in the journals that listed in noteworthy indexes would be higher (24). Although it was claimed that the citations received by $\mathrm{CR} / \mathrm{S}$, published in an average ORL journal or that of higher IFs, are similarly not high (20), there were positive correlations between the value of IFs of the journals with mean citation counts of $\mathrm{CR} / \mathrm{S}$ in this study.

In a recently released national paper, Susaman and Erdăg (25) underlined that while the highest number of case reports was in the field of head and neck surgery and in the category of rare diseases and unexpected conditions, citations they received were not noteworthy, which was also not different from the international literature.

Over the last several years, new peer-reviewed journals that exclusively publish CR/S have emerged. These are mostly open-access journals with considerably high acceptance rates (1). Because CR/S do not rank highly in the hierarchy of evidence and are not frequently cited, they are seldom published by high-impact medical journals. Laccourreye et al. (23) showed that $5 \%$ of the $\mathrm{CR} / \mathrm{S}$ submissions was accepted for publication in the journal of 'European Annals of Otolaryngology Head \& Neck Diseases', whereas, 7\% were not resubmitted by the authors and $88 \%$ were rejected.

The development of modern experimental techniques may have lead clinical trials to supersede observations, $\mathrm{CR} / \mathrm{S}$ in this context. The descriptions of new syndromes and groundbreaking new modalities are not being made lately unless they make novel discoveries that worth citing. However, CR/S type of papers advance medical knowledge and constitute data for EBM, especially when they were combined with follow-up reports. Case reports also provide information on new conditions, examination and imaging procedures, treatment modalities, complications, and side effects, with literature, have also induced the formation of hypotheses for more comprehensive and sophisticated studies $(5,13,24)$. Moreover, the positive correlation between the number of cases presented and the number of citations is a critical finding of this study. Perhaps, as the number of cases increases, the more value a $\mathrm{CR} / \mathrm{S}$ is taken due to the more knowledge and experience reported about these cases in EBM.

The findings of the present study, on the bibliometric and citation journey of $\mathrm{CR} / \mathrm{S}$ in SCI ORL journals, can be beneficial for the academicians, who are interested in writing $\mathrm{CR} / \mathrm{S}$. In fact, case reporting is like writing an academic story of a particular medical condition and an entry pathway for young physicians into the medical publication world. Alternatively, the findings of this study will provide the 
editorial boards of the journals with an evidence-based guide to evaluate their attitudes toward CR/S submissions.

\section{Conclusion}

In this study, the publication and citation aspects of $\mathrm{CR} / \mathrm{S}$ in SCI ORL journals were served to literature. The decline in publication and citation rates of $\mathrm{CR} / \mathrm{S}$ in $\mathrm{SCI}$ journals should not discourage the academicians submitting their works, instead they should become aware of the possibly accepted and cited types of CR/S.

Ethics Committee Approval: Ethics committee approval was not obtained for this study, as no human subject was included in this bibliometric research.

Informed Consent: Since this bibliometric research did not include any human or animal subject, informed consent was not obtained.

Peer-review: Externally peer-reviewed.

Conflicts of Interest: No conflict of interest was declared by the authors.

Financial Disclosure: The authors declared that this study received no financial support.

\section{Authorship Contributions}

Concept: N.G.Y.A., M.A., Design: N.G.Y.A., M.A., Data Collection and/or Processing: N.G.Y.A., M.A., Analysis and/or Interpretation: N.G.Y.A., M.A., Literature Search: N.G.Y.A., M.A., Writing: N.G.Y.A., M.A.

\section{Main points}

- Only 10\% of CR/S articles in SCI-indexed ORL journals (published during the period January 1 ${ }^{\text {st }}, 2012$ and December $31^{\text {st }}$,2016) had $\geq 10$ citations by October 2019.

- The most published CR/S were in the field of 'pediatric ORL', whereas 'general ORL' field got the highest citations.

- The most published CR/S were in the category of 'rare cases', whereas 'treatment' category got the highest citations.

- Changes in publication and citation numbers may reflect changing interests in $\mathrm{CR} / \mathrm{S}$ type of articles in the field of ORL.

\section{References}

1. Akers KG. New journals for publishing medical case reports. J Med Libr Assoc 2016; 104: 146-9. [Crossref]

2. Nissen T, Wynn R. The history of the case report: a selective review. JRSM Open 2014; 5: 1-5. [Crossref]

3. Murad MH, Asi N, Alsawas M, Alahdab F. New evidence pyramid. Evid Based Med 2016; 21: 125-7. [Crossref]
4. Garfield E. The evolution of the Web of Science from the Science Citation Index. BiD: textos universitaris de biblioteconomia i documentació, núm 2016: 37. [Crossref]

5. Albrecht J,Werth VP, Bigby M. The role of case reports in evidencebased practise, with suggestions for improving their reporting. J Am Acad Dermatol 2009; 60: 412-7. [Crossref]

6. Firat AC, Araz C, Kayhan Z. Case reports: should we do away with them? J Clin Anesth 2017; 37: 74-6. [Crossref]

7. Flood LM, Kenyon G.The ENT case report in the era of evidencebased medicine: a defence and a guide. J Laryngol Otol 2009; 123: 1-3. [Crossref]

8. Impact Factor Search. Available at: http://www.bioxbio.com/if/. (Accessed 10 December 2019). [Crossref]

9. Tolwani A. Research model designs. Nordness R, editor. Epidemiology and Biostatistics Secrets. Philadelphia: Mosby, Elsevier; 2006. [Crossref]

10. Janicek M. Clinical Case Reporting in Evidence-Based Medicine. Oxford: Butterworth Heinemann; 1999. [Crossref]

11. Porta M. A dictionary of epidemiology/edited for the International Epidemiological Association, 5th ed. UK: Oxford University Press; 2008. p.33. [Crossref]

12. Last JM. A dictionary of epidemiology/edited for the International Epidemiological Association, 4th edn. UK: Oxford University Press; 2001. [Crossref]

13. Abu-Zidan FMi Abbas AK, Hefny AF. Clinical 'case series': a concept of analysis. African Health Sciences 2012; 4: 557-62. [Crossref]

14. Alpi KM, Evans JJ. Distinguishing case study as a research method from case reports as a publication type. J Med Libr Assoc 2019; 107: 1-5. [Crossref]

15. Tamati TN, Gilbert JL, Pisoni DB. Influence of early linguistic experience on regional dialect categorization by an adult cochlear implant user: a case study. Ear Hear 2014; 35: 383-6. [Crossref]

16. van Beelen E, Leijendeckers JM, Huygen PLM, Admiraal RJC, Hoefsloot LH, Lichtenbelt KD, et al. Audiometric characteristics of two Dutch families with non-ocular Stickler syndrome (COL11A2). Hear Res 2012; 291: 15-23. [Crossref]

17. Lizé F, Verillaud B, Vironneau P, Blancal JP, Guichard JP, Kania R. Septic cavernous sinus thrombosis secondary to acute bacterial sinusitis: a retrospective study of seven cases. Am J Rhinol Allergy 2015; 29: 7-12. [Crossref]

18. Packer CD, Katz RB, Iacopetti CL, Krimmel JD, Singh MK. A case suspended in time: the educational value of case reports. Acad Med 2017; 92: 152-6. [Crossref]

19. Edelmayer LW, Fenton JE, Yellin SA, Shearer DJ, Coelho DH. Case report classics in otolaryngology - head and neck surgery: citation analysis. J Laryngol Otol 2018; 132: 651-6. [Crossref] 
20. Coelho DH, Edelmayer LW, Fenton JE. A century of citation classics in otolaryngology-head and neck surgery journals revisited. Laryngoscope 2014; 124: 1358-62. [Crossref]

21. Lenzi R, Fortunato S, Muscatello L. Top-cited articles of the last 30 years (1985-2014) in otolaryngology - head and neck surgery. J Laryngol Otol 2016; 130: 121-7. [Crossref]

22. Fenton JE, Khoo SG, Ahmed I, Ullah I, Shaikh M. Tackling the case report. Auris Nasus Larynx 2004; 31: 205-7. [Crossref]

23. Laccourreye O, Bonfils P, Denoyelle F, Garrel R, Jankowski R, Karkas A, et al. Analysis of case reports submitted to the European
Annals of Otolaryngology Head \& Neck Diseases. Eur Ann Otorhinolaryngol Head Neck Dis 2016; 133: 171-4. [Crossref]

24. Albrecht J, Meves A, Bigby M. Case reports and case series from Lancet had significant impact on medical literature. J Clin Epidemiol 2005; 58: 1227-32. [Crossref]

25. Susaman N, Erdag TK. Characteristics and citation analysis of case reports published in Turkish national otorhinolaryngology journals. Journal of Ear Nose Throat and Head Neck Surgery 2021; 29: 107-12. [Crossref] 